\title{
Growth Determinants of Micro and Small Enterprises in Ethiopia: Evidence from Selected Woredas of Gurage Zone
}

\author{
Abel Dula Wodajo', Endalkachew Kabtamu Mekonen², Solomon Fiseha Abera² \\ ${ }^{1}$ Department of Management, Wolkite University, Wolkite, Ethiopia \\ ${ }^{2}$ Department of Economics, Wolkite University, Wolkite, Ethiopia \\ Email: abel.server@gmail.com, endalkhabte@gmail.com, meazi04@gmail.com
}

How to cite this paper: Wodajo, A. D., Mekonen, E. K., \& Abera, S. F. (2020). Growth Determinants of Micro and Small Enterprises in Ethiopia: Evidence from Selected Woredas of Gurage Zone. Open Journal of Business and Management, 8, 1339-1360. https://doi.org/10.4236/ojbm.2020.83086

Received: March 9, 2020

Accepted: May 26, 2020

Published: May 29, 2020

Copyright () 2020 by author(s) and Scientific Research Publishing Inc. This work is licensed under the Creative Commons Attribution International License (CC BY 4.0).

http://creativecommons.org/licenses/by/4.0/

\begin{abstract}
The study attempts to provide two integrated growth models, sales and employee growth model to assess the factors that determine Micro and Small Enterprises (MSE's) growth. Cluster sampling techniques was employed and a total of 348 samples were selected. The data were collected through questionnaires, key-informant interviews and focus group discussions. Both descriptive and empirical analysis methods were employed and the descriptive part was analyzed using central tendency measures, dispersion, while the empirical analysis applied confirmatory factor analysis, first order structural analysis and second order structural analysis. The study elucidates the inter-relationship among the four determinants of growth. According to the path analysis results, internal capabilities and business structure is key dimension that directly affects MSE's growth (through innovation and imitations and number of products with employee incentives), and followed by human capital, social capital and access to external resources. A number of variables influence MSE's growth. These may affect the growth directly, indirectly, or both. Human capital of owner-managers had direct and indirect effect on MSEs' growth. In particular, training with work experience in same field has substantial positive effect on MSE's growth. In addition to the direct effect, it has indirect positive effect via variables in social capital (such as organizational network with network maintenance and resources sharing with enterprise) and internal capabilities and business structure. The results with respect to access to external resources reveal both direct and indirect effects on MSEs' growth. Especially, access to inputs (labor, raw material and finance) has substantial significant positive effect on growth. In the case of internal capabilities and business structure, the result suggests that it has direct positive effect on MSEs' growth through innovations and imitations and number
\end{abstract}


of products with employee incentives. Following the result, it is recommended that to best promote the growth of MSE's in the study area, concerned body should take the following measures: 1) enhance human capital through training and technical assistance programs; 2) promote different form of innovations and imitations such as product, process, work practice, marketing and supply relations by increasing contacts with organizational networks and enhancing; 3) support collaboration with business support institutions and other organizations can serve to acquire the expertise and services that currently are lacking in the industry.

\section{Keywords}

Employee Growth, Sales Growth, Human Capital, Social Capital, Micro and Small Enterprise, Structural Equation Model, Gurage Zone

\section{Introduction}

The health of small business sector is very important for the overall economic growth potential and future strength of an economy. There has been more written about small business growth in recent years than any other aspect of sectors (Rami \& Ahmed, 2007). The Small Enterprise (SE) sector generates substantial employment opportunities and economic output in developed and developing countries (Nishantha, 2013). Micro and small enterprises act as providers for goods and services, facilitate transfer of technology, create employment and create wealth. Some factors influence growth mainly as facilitators while others act mainly as growth deterrents (Davidsson, 1989). Currently, for many countries, MSE's are considered as the pillar of their growth and development. The importance of the sector for economic development has been at the center of policy for many years (Liedholm et al., 1994). Supporting MSEs can be understood as "growth with redistribution" that means equitable distribution of income with greater growth can occur simultaneously. He was also argued for the support of MSE's, because they serve as an entrepreneurial "seed bed" with entrepreneurs graduating to run or serve as vehicle for larger industries. As documented in World Bank (2011), many African countries recognize the centrality of MSE's sector for economic growth and diversification, but their domestic MSE's sector is still small and thin. This sector is the engine of economic growth, stimulating entrepreneurship and innovation and promoting competition and productivity.

The private sector is expected to play a key role in Ethiopia's journey to become a middle income country by 2025 . However, this projection will not be achieved without recognizing the crucial role that MSE's play for increment of rural urban linkages, increment of export or reduce imported goods and service which in turn reduces the trade deficit, base for large industries, solution for unemployment (reduction of wasted man power), and reduce poverty and in- 
come inequality in the country. While a considerable amount is known about the factors that affect the success of micro and small sized businesses, this knowledge continues to be imperfect and a large number of questions remain unanswered regarding those business sector in developing countries (Rami \& Ahmed, 2007). Recent empirical studies were revolved around assessing determinants that foster or hinder MSE's growth classifying them as internal and external factors. Moreover, studies assess the effects of growth by conceptualizing that growth can be measured in terms of sales, employment growth and firm profitability. The studies measuring the effects of growth are most often focusing on assessing of the effect of different determinants. Interestingly these studies tend to ignore the intermediate process of managing these determinants (Degenhardt, Stamm, \& Zehdnicker, 2002). In view of empirical literatures, there are different studies conducted to study the determinants of MSE's growth in different areas, but they emphasize mainly to find the problems through exploratory research. Previous studies were excess to depict the determinants of growth through conceptualizing the multi-dimensional factors. To mention some among the classification of those factors that determine MSE's growth are internal and external environmental factors, contextual factors, political, social, economic, technological and organizational factors are the leading. However, the present study is not in a opposition to support or contradict the multidimensionality of the factors that determine MSE's growth, but the study conceptualize lack of studies that emphasize on the mediating and moderating role of different factors that determine MSE's growth, lack of integration of different findings into a more comprehensive theory of growth, shortage of studies that focus on multi-directionality of growth itself, lack of focus on people issues, lack of combining different levels of analysis (individual, team, organization, environment); rather low level of link between empirical findings and theory building are among the main problems that the present study identified as a research gap and would like to fill (Darnay \& Magee, 2007).

The performance of MSE's sector in Ethiopia is poor compared with similar sectors in another African country such as South Africa, Kenya, Uganda and Tanzania. Small businesses and enterprises in Ethiopia are characterized by acute shortage of finance, lack of technical skills, lack of training opportunities and raw materials, poor infrastructure and over-tax (Abeka, 2011). According to MSE's Development Strategy of Ethiopia (2015), the main focus of the government is creating job opportunities through MSE's development, and alleviate poverty and enhance the sector to be base for industrial development in the country and to show that MSE's are important to the economic and social development of the country and facilitates rural and urban economic linkage and boost the economy, promotes entrepreneurship culture, strengthen self-employment and serves as fertile ground for the emergence of Medium and Large Industries in the countries. In realizing this goal, the government may face detrimental factors for the growth of the sector; therefore, it is crucial to be able to dig out these detrimental factors and make confirmatory analysis to realize the goal. 
Thus, to have a proper intervention for the growth of MSE's at national level in general and Gurage zone in particular intensive investigation is required. That is why this study is tried to identify the growth determinants of MSE's growth with the objectives of to identify the factors that affect growth of MSE's, to evaluate how the determinant factors are interacting each other and to examine whether sales or employment growth model fit the study area situation. As many findings show MSE's are the engine and accelerator of national economic growth and development. As Ethiopia is developing country the growths of MSE's sector are vital to takeoff in to middle income countries. However, to make sound policy that boost up the growth and expansion of the sector and to create healthy environment policy maker's needs scientifically investigated findings of study. Therefore, this study would provide some insights for policy maker for developing country in general and Gurage zone in particular. It also provides information for individuals and owners of MSE's and institutions.

\section{Methodology of the Study}

The data used in this study were collected from two sources, namely primary and secondary sources. The primary data were collected through questionnaires, interviews and focus group discussion. The questionnaires included open ended and close ended questions. Secondary data include published and unpublished materials collected from stakeholders of MSE's. The questionnaires used in this study is adapted from (Nishantha, 2013) with modification to suit the study area. The target group of this study is MSE's that involve in manufacturing, construction, service, trade and urban agriculture. According to Gurage zone trade and industry department (2015), there are 2665 MSE's in Gurage zone where construction accounts 489 (18.34\%), manufacturing 424 (15.9\%), service 650 (24.39\%), trade 908 (34.07\%) and urban agriculture 194 (7.27\%). After clustering the concentration of MSE's into three strata's (high concentration, medium concentration and low concentration), six Woredas were selected purposively. Finally, in each cluster, two woreda are included based on their concentration. The selected clusters are Butajira (623) and Wolkite (663) from high concentration, Abeshge (171) and Gumer (199) from medium concentration, Mareko (60) and Endegagni (45) from low concentration. Once the sample Woredas are selected, the researcher stratified the MSE's into five sub sectors. These are manufacturing, construction, service, trade and urban agriculture sector. In this stud, multi stage sampling techniques as employed. Using this sampling technique the researchers use cluster sampling as a first step and stratified sampling techniques to select representative samples from the five strata. The researcher used (Yamane, 1967) formula to select a samples.

$$
\begin{gathered}
n=\frac{N}{1+N \times e^{2}} \\
n=\frac{2665}{1+2665 \times 0.05^{2}} \Rightarrow n=347.79 \approx 348
\end{gathered}
$$


where $n=$ sample size, $N=$ target population, $e=$ confidence level at $0.05 \%$ or $95 \%$. Then, the sample size in each Woredaby sectors is determined proportionately. To select the sample unit from each sub sectors simple random sampling technique was used.

The researchers follow three main processes as a statistical plan: Confirmatory factor analysis CFA of measurement model, first order structural analysis and second order Structural Analysis. Factor analysis would be used to determine the number of factors associated with human capital (HC), social capital (SC), access to external resources (AER) and internal capabilities and business structures (IC\&BS). Because it is considered as the most widely used multivariate statistical procedures in applied research endeavors across multitude of domains (Brown, 2006). Robert (2007) claim that multilevel regression is best used when the power and versatility of ordinary least squares (OLS) regression and its established correctives have been exhausted. He added that the most important difference between OLS regression and multilevel regression is the thorough theoretical and substantive knowledge base needed to properly specify a multilevel model. First-generation techniques have been widely applied by social science researchers. However, for the past 20 years, many researchers have increasingly been turning to second-generation techniques to overcome the weaknesses of first-generation methods (Hair, et al., 2014). This method is referred to as structural equation modeling (SEM), which enable researchers to incorporate unobservable variables measured indirectly by indicator variables. They also facilitate accounting for measurement error in observed variables (Chin, 1998, cited in Hair et al., 2014). Regardless of whether a researcher is using first or second generation multivariate analysis methods, several considerations are necessary in deciding to use multivariate analysis, particularly SEM, these are Variate, Measurement (Hair et al., 2014), Measurement Scales, Coding, and Data Distributions.

\section{Result and Discussion}

To analyze the collected data in line with the overall objective of the study, statistical procedures were carried out using SPSS statistics and SPSS Amos version 20 . In all cases alpha (significance value) is set at 0.05 , to test at 95 percent confidence level. In this section the researcher presented data analysis performed through providing distinct explanations with regard to the measurement model and structural model of the study. Assessment of reflective measurement models includes composite reliability to evaluate internal consistency, individual indicator reliability, and average variance extracted (AVE) to evaluate convergent validity. In addition, the Fornell-Larcker criterion and cross loadings are used to assess discriminant validity (Hair, Hult, Ringle, \& Sarstedt, 2014; Hair, Black, Babin, Anderson, \& Tatham, 2006). The results are presented in four parts. The first section presents the characteristics of the sample, followed by presentation of descriptive statistics. The third section analyzes the factor analysis results, and 
the final section presents the discussion of results.

As revealed in Table 1, 34.1\% of entrepreneurs surveyed are male and $65.9 \%$ of them are female. The entrepreneurs' ages vary from the minimum 19 years to maximum age of 58 years. The average age for the sample surveyed is 29.2 year with a standard deviation of 5.98. Majority of the entrepreneurs are operating in the two city administration namely Butajira (39.4\%) and Wolkite (32.8\%), whereas a relatively small proportion of entrepreneurs are surveyed from other four Woredas, Abeshge (10\%), Mareko (4.0\%), Gumer (10.6\%), and Endegagni (2.8\%). In addition, among surveyed entrepreneurs $59.1 \%$ the sample are married whereas

Table 1. Characteristics of micro and small enterprises in Gurage zone.

\begin{tabular}{|c|c|c|c|c|c|}
\hline Entrepreneurial Characteristics & \multicolumn{3}{|c|}{ Frequency } & \multicolumn{2}{|c|}{ ercentage } \\
\hline & \multicolumn{5}{|c|}{ Sex of Respondents } \\
\hline Male & \multicolumn{2}{|r|}{109} & \multicolumn{3}{|c|}{34.1} \\
\hline Female & \multicolumn{2}{|r|}{211} & \multicolumn{3}{|c|}{65.9} \\
\hline \multicolumn{6}{|l|}{ Location of MSE's } \\
\hline Butajira & \multicolumn{2}{|r|}{126} & \multicolumn{3}{|c|}{39.4} \\
\hline Wolkite & \multicolumn{2}{|r|}{105} & \multicolumn{3}{|c|}{32.8} \\
\hline Abeshge & \multicolumn{2}{|r|}{32} & \multicolumn{3}{|c|}{10.0} \\
\hline Mareko & \multicolumn{2}{|r|}{14} & \multicolumn{3}{|c|}{4.4} \\
\hline Gumer & \multicolumn{2}{|r|}{34} & \multicolumn{3}{|c|}{10.6} \\
\hline Endegagni & \multicolumn{2}{|r|}{9} & \multicolumn{3}{|c|}{2.8} \\
\hline \multicolumn{6}{|l|}{ Marital Status } \\
\hline Married & \multicolumn{2}{|r|}{189} & \multicolumn{3}{|c|}{59.1} \\
\hline Single & \multicolumn{2}{|r|}{123} & \multicolumn{3}{|c|}{38.4} \\
\hline Divorced & \multicolumn{2}{|r|}{2} & \multicolumn{3}{|c|}{0.6} \\
\hline Widowed & \multicolumn{2}{|r|}{6} & \multicolumn{3}{|c|}{1.9} \\
\hline \multicolumn{6}{|l|}{ Types of Sector } \\
\hline Trade & \multicolumn{2}{|r|}{75} & \multicolumn{3}{|c|}{23.4} \\
\hline Service & \multicolumn{2}{|r|}{87} & & 27.2 & \\
\hline Manufacturing & & 65 & & 20.3 & \\
\hline Construction & & 61 & & 19.1 & \\
\hline Urban agriculture & & 32 & & 10.0 & \\
\hline & Scale Va & ariables & & & \\
\hline & Mean & S.E. & Standard Deviation & Min & Max \\
\hline Age of Respondents & 29.2 & & 5.10 & 19 & 58 \\
\hline Sales growth & 817.34 & 155.43 & 2736.65 & -80 & 29900 \\
\hline Employment Growth & 58.76 & 9.40 & 165.76 & -70 & 2437.50 \\
\hline
\end{tabular}

Source: Survey data (2016). 
$38.4 \%, 0.6 \%$, and $1.9 \%$ are single, divorced and widowed entrepreneurs, respectively. Moreover, Table 1 gives as an evidence regarding the types of sectors entrepreneurs' involved in such as trade (23.4\%), service (27.2\%), manufacturing (20.3\%), and construction (19.1\%) and urban agriculture (10.0\%). A wide variety of enterprise growth measures have been used in the literature such as sales and employment, or more subjective measures (Wiklund, 2009). Therefore, in the present study both Sales and Employee Growth Index as the growth measure (in Table 2) are used. Owner-managers in the survey were asked to record the level of sales and employment in their firm in 2014 and 2015. The employment growth index was calculated as 2015 employment minus 2014 employment, divided by 2014 employment. This growth index variable is asymptotically normally distributed, and statistically appropriate. The sales growth index was calculated as 2015 sales minus 2014 sales, divided by 2014salesthis growth index variable is asymptotically normally distributed, and statistically appropriate.

Where, SG is sales growth, sale 2015 is current year sales (2015), sale 2014 is base year sale (2014), EMP2015 is number of employed labour at current year (2015), and EMP14 is number of employed labour at base year (2014). As shown in Table 2, average sales growth is 817.34 (in Birr) with standard deviation of 2736.65 , minimum value of 80 and maximum value of 29,900 (Birr). Similarly, the average employment growth for the sampled survey is 58.76 with standard deviation of 165.756 minimum value of (70) and maximum value of 2437.50 .

\subsection{Measurement Model Analysis}

As Nishantha B. (2011) noted, a valid and reliable measure of employee and sales growth is needed to advance research and practice in the area of growth theory. Determinants of employee and sales growth constructs was used as a full scale score as well as distinct subscales. The determinants of employee and sales growth construct scale have adequate reliability and validity with reported internal consistency reliability between 0.82 and 0.87 for the full scale and subscales (Nishantha, 2011). For this study reliability of scales measuring human capital, social capital, access to external resources and internal capabilities and business structure were tested using Cronbach's Alpha coefficients and result are reported in Table 3.

The researchers tested reliability of the items measuring the four dimensions of micro and small enterprises growth determinants by means of the internal

Table 2. Definitions of variables of growth.

\begin{tabular}{cc}
\hline Variable & Definition \\
\hline Sales growth & SG $=\frac{\text { Sale2015 }- \text { sale2014 }}{\text { Sale2014 }} * 100$ \\
Employee growth & EG $=\frac{\text { EMP2015 }- \text { EMP2014 }}{\text { EMP2014 }} * 100$ \\
\hline
\end{tabular}


Table 3. Internal consistency of Latent variables.

\begin{tabular}{cccc}
\hline Factors & $\begin{array}{c}\text { Cronbach's } \\
\text { Alpha }\end{array}$ & $\begin{array}{c}\text { Cronbach's Alpha Based } \\
\text { on Standardized Items }\end{array}$ & Items \\
\hline Human Capital & 0.736 & 0.810 & 7 \\
Social Capital & 0.559 & 0.786 & 5 \\
Access to External Resources Dimension & 0.741 & 0.818 & 6 \\
Internal Capabilities \& Business Structure & 0.568 & 0.709 & 5 \\
\hline
\end{tabular}

Source: Survey data (2016).

consistency method. As reported in Pallant (2005), this can be estimated by means of a reliability coefficient, such as Cronbach's alpha, measuring the internal consistency of multidimensional scales. In this respect, the minimum advisable level is 0.7 (Nunnally, 1978), although it may be reduced to 0.6 in exploratory research or even to 0.55 (Hair et al., 1995). In line with these suggestions after performing a reliability analysis using Alpha the researcher's confirmed that all the instruments employed in this study are above the minimum level of 0.7 with the exception of internal capabilities and business structure and social capita that have 0.568 and 0.559 , respectively. With respect to suggestions given by (Hair et al., 1995) incorporating these variables into the analysis may not resulted a problem. The researchers conducted a pilot survey by distributing the instrument mentioned in method of data collection section to MSE's operators in Cheha Woreda in order to assure the validity of the instrument developed. Participants in the pilot study constitute10 MSE's operators located in Gurage zone, Cheha Woreda. The researcher's asked those individuals to assess each item on the survey and to identify items that need to be reworded, items that have to be eliminated if they did not add value and items that should be added in order to adequately measure determinants. Even though the researcher's incorporated 77 items, responses from these individuals were used to develop the final version of the survey which includes only 77 items. With this approach, the researcher's established content validity of survey instrument. According to Nishantha (2011), using 97 sample respondents in Sri Lanka, The initial 63-item analysis yielded four-factor structure, using varimaxrotation; these initial analyses were conducted on data collected using different combinations of measurement scale. Therefore, for the present study, the researchers developed an instrument from the collected works of many researchers. The final version used for analysis after conducting a pilot survey was hypothesized as four factors with a total of 77 items. After testing the measurement model the researchers used the 23 observable items extracted from the summated result of the 77 items.

\subsection{Data Considerations and Structural Model Analysis}

According to Donna (2009), there are several important data considerations that need to be addressed, including missing data, normality, and sample size requirements. Before proceeding with the analysis, the secriteria must be consi- 
dered to check the suitability of the study for factor analysis as well as structural equation models (Pallant, 2005). As part of preparing data for analysis, it is vital to look for missing data. Even though two recommended approaches were mentioned in (Donna, 2009); which are, 1) run the analysis with missing data allowing the software to estimate parameters (i.e. direct $\mathrm{ML}$ ), or 2) impute (i.e. use computer software to replace missing values with plausible guesses). The researcher's confirmed the dataset used in this research has shown no missing value, $(\mathrm{n}=320 ; 100 \%)$. Skewness and kurtosis indices are presented. Following (Donna, 2009), suggestion that only variables with skew index absolute values greater than 3 and kurtosis index absolute values greater than 10 are of concern, none of the variables in this analysis has problematic levels of skewness or kurtosis. With a valid sample size of 320 for this research study (Donna, 2009), would consider this a large sample size. The sample size; as suggested by (Tabachnick, 2007), the researcher needs to have at least 300 cases for factor analysis, however, a small sample size (e.g. 100 cases) should be sufficient if solutions have several high loading marker variables (above 0.80). According to (Hair et al., 2006), suggestion that a researcher generally would not factor analyze a sample of fewer than 50 observations, and preferably the sample size should be 100 or large. In line with the above justification the researcher justifies using 320 cases in the research is feasible for structural equation model analysis.

Amos (analysis of moment structure) graphics follows the conventions of structural equation modeling (SEM) diagrams. The ovals represent latent (unobserved) variables, in this case, human capital dimension, represented by summated score of training with experience in the same field, education with experience in government sector, self-learning with work experience in different field, self-learning with ownership experience in different field, family tradition, ownership experience in same field, technical and professional education; social capital dimension represented by summated score of organizational network and network maintenance, resources sharing with MSE's, government supportive activities, sharing consultancy with social network, supportive network with financial institutions; internal capabilities and business structure denoted by summated score of innovation and imitations, number of products with employee incentives, ownership structure with stock related innovations, market related innovations with employee benefits, new products and new machines; and access to external resources represented by summated score of access to credit and credit information, access to inputs, capital source from finance companies, supplier availability, competition from large and medium enterprises, access to market represent the four subscales of the employee and sales growth determinants.

The rectangles represent observed variables, which are actual determinants of MSE's growth construct summated scores indicated in bracket. The curved double-headed arrows represent the correlations or covariance's among the latent variables (for standardized and unstandardized solutions, respectively), and 
the straight single-headed arrows represent the factor loadings of the observed variables on the latent variables. The small circles with arrows pointing from the circles to the observed variables represent errors or unique factors that each latent variable has a 1 next to the path from it to one observed variable (e.g. from human capital dimension to training with experience in the same field). This serves to constrain the parameter and define the scale of the latent variable as it was suggested by (Arbuckle, 2012) each latent variable must be scaled. So all the procedures are performed with due considerations pertinent to the micro and small enterprises growth determinant and analysis was done according to (Arbuckle, 2012) manual. To see the detailed structure all those items representing the variables that are used as a summated score, were entered as well as calculated in SPSS statistics version 20 and imported to Amos Graphics software. The standardized estimates output provided by Amos 20.0 using ML estimation is presented in Table 4.

The factor loadings are shown on the arrows from the latent variables to the observed variables in Table 4, where Amos do the algorithm to come up with the standardized regression weight where it indicates the direct relationship between each observed variables and the construct it was supposed to measure (indicated by a single arrow). Table 4 shows the standardized and unstandardized regression weight in conjunction with explicitly pointing out "z" score (critical ratio) by dividing the regression weight estimate by the estimate of its standard error to identify whether it is significance or not significant. Thus, as per Table 4, when we look into the second row the path from Human capital Dimension (HCD) construct to education with experience in government sector have the regression weight estimate, 1.714 , has a standard error of about 0.286 and $\mathrm{z}=$ $1.714 / 0.286=5.984$. In other words, the regression weight for HCD in the prediction of the probability of getting a critical ratio large 5.984 in absolute value is less than 0.001 . The probability of getting a critical ratio as large as 5.984 in absolute value is less than 0.001 . The statements are approximately correct for large samples under suitable assumptions. So according to the table following the above interpretation the researchers concluded that only: The probability of getting critical ratio as large as 1.214 in absolute value is 0.225 , in other words, the regression weight for HCD in the prediction of family tradition is not significantly different from zero at the 0.05 level (two-tailed). The probability of getting critical ratio as large as 1.68 in absolute value is 0.093 , in other words, the regression weight for SCD in the prediction of government support activities is not significantly different from zero at the 0.05 level (two-tailed). The probability of getting critical ratio as large as 0.939 , in absolute value is 0.347 . In other words, the regression weight for SCD in the prediction of sharing consultancy service network is not significantly different from zero at the 0.05 level (two-tailed). The probability of getting critical ratio as large as 0.105 , in absolute value is 0.917. In other words, regression weight for SCD in the prediction of supportive network with financial institutions is not significantly different from zero at 0.05 levels. The probability of getting critical ratio as large as 0.798 , in absolute value 
Table 4. Standardized and unstandardized regression weight (Factor loading of observable variables on latent variables).

\begin{tabular}{|c|c|c|c|c|c|c|c|c|}
\hline Path & & & Estimate & S.E. & C.R. & $P$ & Label & $\begin{array}{c}\text { Standardized } \\
\text { Regression } \\
\text { Estimate }\end{array}$ \\
\hline $\begin{array}{l}\text { Training with work } \\
\text { experience in same field }\end{array}$ & $\leftarrow$ & $\mathrm{HCD}$ & 1.000 & & & & & 0.459 \\
\hline $\begin{array}{l}\text { Education with experience } \\
\text { in government sector }\end{array}$ & $\leftarrow$ & HCD & 1.714 & 0.286 & 5.984 & $* * *$ & a1_1 & 0.254 \\
\hline $\begin{array}{l}\text { Self-learning with work } \\
\text { experience in different field }\end{array}$ & $\leftarrow$ & HCD & 1.459 & 0.176 & 8.291 & $* * *$ & a2_1 & 0.379 \\
\hline $\begin{array}{l}\text { Self-learning with ownership } \\
\text { experience in different field }\end{array}$ & $\leftarrow$ & HCD & 1.415 & 0.137 & 10.319 & $* * *$ & a3_1 & 0.706 \\
\hline Family tradition & $\leftarrow$ & $\mathrm{HCD}$ & -0.528 & 0.435 & -1.214 & 0.225 & a4_1 & -0.055 \\
\hline $\begin{array}{l}\text { Ownership experience } \\
\text { in same field }\end{array}$ & $\leftarrow$ & HCD & 0.744 & 0.099 & 7.512 & $* * *$ & a5_1 & 0.411 \\
\hline $\begin{array}{l}\text { Technical and } \\
\text { professional education }\end{array}$ & $\leftarrow$ & HCD & 0.869 & 0.154 & 5.635 & $* * *$ & a6_1 & 0.282 \\
\hline $\begin{array}{l}\text { Organizational network } \\
\text { and network maintenance }\end{array}$ & $\leftarrow$ & SCD & 1.000 & & & & & 0.969 \\
\hline Resources sharing with SMEs & $\leftarrow$ & SCD & 0.977 & 0.030 & 32.358 & $* * *$ & a7_1 & 0.952 \\
\hline Government supportive activities & $\leftarrow$ & SCD & 0.014 & 0.008 & 1.680 & 0.093 & a8_1 & 0.066 \\
\hline $\begin{array}{l}\text { Sharing consultancy } \\
\text { with social network }\end{array}$ & $\leftarrow$ & SCD & 0.007 & 0.007 & 0.939 & 0.347 & a9_1 & 0.033 \\
\hline $\begin{array}{l}\text { Supportive network } \\
\text { with financial institutions }\end{array}$ & $\leftarrow$ & SCD & 0.001 & 0.007 & 0.105 & 0.917 & a10_1 & 0.001 \\
\hline Innovation and imitations & $\leftarrow$ & AIBSD & 1.000 & & & & & 0.823 \\
\hline $\begin{array}{l}\text { Number of products } \\
\text { with employee incentives }\end{array}$ & $\leftarrow$ & AIBSD & 0.046 & 0.058 & 0.798 & 0.425 & a11_1 & 0.032 \\
\hline $\begin{array}{l}\text { Ownership structure } \\
\text { with stock related innovations }\end{array}$ & $\leftarrow$ & AIBSD & 0.202 & 0.032 & 6.285 & $* * *$ & a12_1 & 0.218 \\
\hline $\begin{array}{l}\text { Market related innovations } \\
\text { with employee benefits }\end{array}$ & $\leftarrow$ & AIBSD & 0.336 & 0.057 & 5.844 & $* * *$ & a13_1 & 0.239 \\
\hline New products and new machines & $\leftarrow$ & AIBSD & 0.139 & 0.020 & 7.078 & $* * *$ & a14_1 & 0.345 \\
\hline $\begin{array}{l}\text { Access to credit } \\
\text { and credit information }\end{array}$ & $\leftarrow$ & AERD & 1.000 & & & & & 0.563 \\
\hline Access to inputs & $\leftarrow$ & AERD & 0.731 & 0.072 & 10.144 & $* * *$ & a15_1 & 0.355 \\
\hline $\begin{array}{l}\text { Capital Sources with credit } \\
\text { from finance companies }\end{array}$ & $\leftarrow$ & AERD & 0.687 & 0.048 & 14.420 & $* * *$ & a16_1 & 0.838 \\
\hline Supplier availability & $\leftarrow$ & AERD & 0.744 & 0.050 & 15.017 & $* * *$ & a17_1 & 0.855 \\
\hline $\begin{array}{l}\text { Competition from large } \\
\text { and medium enterprises }\end{array}$ & $\leftarrow$ & AERD & 0.628 & 0.049 & 12.880 & $* * *$ & a18_1 & 0.553 \\
\hline Access to markets & $\leftarrow$ & AERD & 0.817 & 0.057 & 14.449 & $* * *$ & a19_1 & 0.853 \\
\hline
\end{tabular}

Source: Survey data (2016). 
is 0.425 . In other words, the regression weight for AIBSD in the prediction of number of products with employee incentives is not significantly different from zero at the 0.05 level (two-tailed). According to Tabachnick (2007), in general, the higher the factor loading the better, and typically loadings below 0.30 are not interpreted. As general rules of thumb, loadings above 0.71 are excellent, 0.63 very good, 0.55 good, 0.45 fair, and 0.32 poor. These rules of thumb are based on factor analyses, where factor loadings are correlations between the variable and factor, so squaring the loading yields a variance accounted for. The numbers at the upper right hand corner of each observed variable are the squared multiple correlations for each observed variable this is shown in the table.

As shown in Table 5, it is estimated that the predictors of number of products with employee incentives explain 0.1 percent of its variance. In other words, the error variance of number of products with employee incentives is approximately

Table 5. Squared multiple correlation Amos text results.

\begin{tabular}{lc}
\hline & Estimate \\
\hline Number of products with employee incentives & 0.001 \\
New products and new machines & 0.119 \\
Innovation and imitations & 0.677 \\
Access to market & 0.727 \\
Supportive network with financial institutions & 0.000 \\
Market related innovations with employee benefits & 0.057 \\
Ownership structure with stock related innovations & 0.048 \\
Sharing consultancy with social network & 0.001 \\
Government supportive activities & 0.004 \\
Resources sharing with SMEs & 0.907 \\
Organizational network and network maintenance & 0.940 \\
Technical and professional education & 0.080 \\
Ownership experience in same field & 0.169 \\
Family tradition & 0.003 \\
Self-learning with ownership experience in different field & 0.499 \\
Self-learning with work experience in different field & 0.144 \\
Competition from large and Medium enterprises & 0.306 \\
Supplier availability & 0.732 \\
capital source from finance companies & 0.703 \\
Access to inputs & 0.126 \\
Access to credit and credit information & 0.317 \\
Education with experience in government sector & 0.065 \\
\hline Training with experience in the same field & 0.211 \\
\hline
\end{tabular}

Source: Survey data (2016). 
99.9 percent of the variance of number of products with employee incentives itself. So according to the results exhibited in Table 5, the squared multiple correlation of Innovation and imitations, Access to market, Resources sharing with SMEs, organizational network and network maintenance, supplier availability, capital source from finance companies were acceptable.

As shown in Table 6, the correlations among latent variables next to each double arrow relations are demonstrated. Accordingly, 0.746 is the estimated correlation between AERD and AIBSD, 0.353 is the estimated correlation between AERD and SCD, 0.772 is the estimated correlation between AERD and HCD, 0.557 is the estimated correlation between HCD and SCD, 0.788 is the estimated correlation between HCD and AIBSD, 0.156 is the estimated correlation between SCD and AIBSD. So based on the results it can be easily observed that the relationship between social capital dimension and internal capabilities and business structures have a very week relationships as compared to others. These correlations suggest that the latent variables are somewhat related, as would be expected given that they are all hypothesized to be determinants of employee and sales growth, but the correlations are not so high as to suggest that they are all measuring the same construct (See Table 6).

As shown in Table 7, the standardized total (direct and indirect) effect of HCD (human capital dimension) on SCD is 0.375 . That is, due to both direct (unmediated) and indirect (mediated) effects of HCD on SCD, when HCD goes up by 1 standard deviation, SCD goes up by 0.375 standard deviations. The standardized total (direct and indirect) effect of SCD on SCD is .000. That is, due to both direct (unmediated) and indirect (mediated) effects of SCD on SCD, when SCD goes up by 1 standard deviation, SCD goes up by 0 standard deviations. The standardized total (direct and indirect) effect of AERD on SCD is 0.000. That is, due to both direct (unmediated) and indirect (mediated) effects of AERD on SCD, when AERD goes up by 1 standard deviation, SCD goes up by 0 standard deviations. The standardized total (direct and indirect) effect of AIBSD on SCD is 0.000 . That is, due to both direct (unmediated) and indirect (mediated) effects of AIBSD on SCD, when AIBSD goes up by 1 standard deviation, SCD goes up by 0 standard deviations. For further discussion of direct, indirect and total effects, see Kline (1998: p. 52).

Table 8 demonstrated the standardized direct (unmediated) effect of HCD on

Table 6. Correlation results of Latent variables.

\begin{tabular}{llcc}
\hline & & & Estimate \\
\hline AERD & $\leftrightarrow$ & AIBSD & 0.746 \\
AERD & $\leftrightarrow$ & SCD & 0.353 \\
AERD & $\leftrightarrow$ & HCD & 0.772 \\
HCD & $\leftrightarrow$ & SCD & 0.557 \\
HCD & $\leftrightarrow$ & AIBSD & 0.788 \\
SCD & $\leftrightarrow$ & AIBSD & 0.156 \\
\hline
\end{tabular}

Source: Survey data (2016). 
Table 7. Standardized total effects.

\begin{tabular}{|c|c|c|c|c|}
\hline & $\mathrm{HCD}$ & SCD & AERD & AIBSD \\
\hline Social capital dimension (SCD) & 0.375 & 0.000 & 0.000 & 0.000 \\
\hline Access to external resource dimension (AERD) & 0.790 & 0.012 & 0.000 & 0.000 \\
\hline Internal capabilities and business structure dimension (IBSD) & 0.935 & -0.266 & 0.136 & 0.000 \\
\hline Sales growth & -0.024 & 0.114 & 0.009 & -0.611 \\
\hline Number of new product introduced & 0.063 & -0.018 & 0.009 & 0.067 \\
\hline Introduction of new machines & 0.371 & -0.106 & 0.054 & 0.397 \\
\hline Innovation and imitation & 0.741 & -0.211 & 0.108 & 0.792 \\
\hline Access to markets & 0.680 & 0.011 & 0.861 & 0.000 \\
\hline Supportive network with financial institutions & 0.001 & 0.002 & 0.000 & 0.000 \\
\hline Market related innovations with employ benefits & 0.276 & -0.079 & 0.040 & 0.295 \\
\hline Ownership structure with stock related innovations & 0.267 & -0.076 & 0.039 & 0.285 \\
\hline Sharing consultancy with social network & 0.010 & 0.026 & 0.000 & 0.000 \\
\hline Government supportive activities & 0.017 & 0.046 & 0.000 & 0.000 \\
\hline Resource sharing with SMEs & 0.352 & 0.937 & 0.000 & 0.000 \\
\hline Organizational network and network maintenance & 0.362 & 0.963 & 0.000 & 0.000 \\
\hline Technical and professional education & 0.331 & 0.000 & 0.000 & 0.000 \\
\hline Ownership experience in same field & 0.442 & 0.000 & 0.000 & 0.000 \\
\hline Family tradition & -0.077 & 0.000 & 0.000 & 0.000 \\
\hline Self-learning with ownership experience in different field & 0.721 & 0.000 & 0.000 & 0.000 \\
\hline Self-learning with work experience in different field & 0.381 & 0.000 & 0.000 & 0.000 \\
\hline Competition from large and medium enterprises & 0.445 & 0.007 & 0.563 & 0.000 \\
\hline Suppliers availability & 0.687 & 0.011 & 0.869 & 0.000 \\
\hline Capital Sources with credit from finance companies & 0.670 & 0.011 & 0.848 & 0.000 \\
\hline Access to inputs & 0.300 & 0.005 & 0.380 & 0.000 \\
\hline Access to credit and credit information & 0.467 & 0.007 & 0.591 & 0.000 \\
\hline Education with experience in government sector & 0.254 & 0.000 & 0.000 & 0.000 \\
\hline Training with work experience in same field & 0.480 & 0.000 & 0.000 & 0.000 \\
\hline
\end{tabular}

Source: Survey data (2016).

Table 8. Standardized direct effects.

\begin{tabular}{lcccc}
\hline & HCD & SCD & AERD & AIBSD \\
\hline Social capital dimension (SCD) & 0.375 & 0.000 & 0.000 & 0.000 \\
Access to external resource dimension (AERD) & 0.785 & 0.012 & 0.000 & 0.000 \\
Internal capabilities and business structure dimension (IBSD) & 0.928 & -0.268 & 0.136 & 0.000 \\
Sales growth & 0.493 & -0.050 & 0.092 & -0.611 \\
Number of new product introduced & 0.000 & 0.000 & 0.000 & 0.067 \\
\hline
\end{tabular}




\section{Continued}

\begin{tabular}{|c|c|c|c|c|}
\hline Introduction of new machines & 0.000 & 0.000 & 0.000 & 0.397 \\
\hline Innovation and imitation & 0.000 & 0.000 & 0.000 & 0.792 \\
\hline Access to markets & 0.000 & 0.000 & 0.861 & 0.000 \\
\hline Supportive network with financial institutions & 0.000 & 0.002 & 0.000 & 0.000 \\
\hline Market related innovations with employ benefits & 0.000 & 0.000 & 0.000 & 0.295 \\
\hline Ownership structure with stock related innovations & 0.000 & 0.000 & 0.000 & 0.285 \\
\hline Sharing consultancy with social network & 0.000 & 0.026 & 0.000 & 0.000 \\
\hline Government supportive activities & 0.000 & 0.046 & 0.000 & 0.000 \\
\hline Resource sharing with SMEs & 0.000 & 0.937 & 0.000 & 0.000 \\
\hline Organizational network and network maintenance & 0.000 & 0.963 & 0.000 & 0.000 \\
\hline Technical and professional education & 0.331 & 0.000 & 0.000 & 0.000 \\
\hline Ownership experience in same field & 0.442 & 0.000 & 0.000 & 0.000 \\
\hline Family tradition & -0.077 & 0.000 & 0.000 & 0.000 \\
\hline Self-learning with ownership experience in different field & 0.721 & 0.000 & 0.000 & 0.000 \\
\hline Self-learning with work experience in different field & 0.381 & 0.000 & 0.000 & 0.000 \\
\hline Competition from large and Medium enterprises & 0.000 & 0.000 & 0.563 & 0.000 \\
\hline Suppliers availability & 0.000 & 0.000 & 0.869 & 0.000 \\
\hline Capital Sources with credit from finance companies & 0.000 & 0.000 & 0.848 & 0.000 \\
\hline Access to inputs & 0.000 & 0.000 & 0.380 & 0.000 \\
\hline Access to credit and credit information & 0.000 & 0.000 & 0.591 & 0.000 \\
\hline Education with experience in government sector & 0.254 & 0.000 & 0.000 & 0.000 \\
\hline Training with work experience in same field & 0.480 & 0.000 & 0.000 & 0.000 \\
\hline
\end{tabular}

Source: Survey Data (2016).

AIBSD is 0.928. That is, due to the direct (unmediated) effect of HCD on AIBSD, when HCD goes up by 1 standard deviation, AIBSD goes up by 0.928 standard deviations. This is in addition to any indirect (mediated) effect that HCD may have on AIBSD. The standardized direct (unmediated) effect of SCD on AIBSD is -0.268 . That is, due to the direct (unmediated) effect of SCD on AIBSD, when SCD goes up by 1 standard deviation, AIBSD goes down by 0.268 standard deviations. This is in addition to any indirect (mediated) effect that SCD may have on AIBSD. The standardized direct (unmediated) effect of AERD on AIBSD is 0.136. That is, due to the direct (unmediated) effect of AERD on AIBSD, when AERD goes up by 1 standard deviation, AIBSD goes up by 0.136 standard deviations. This is in addition to any indirect (mediated) effect that AERD may have on AIBSD. The standardized direct (unmediated) effect of AIBSD on AIBSD is 0.000 . That is, due to the direct (unmediated) effect of AIBSD on AIBSD, when AIBSD goes up by 1 standard deviation, AIBSD goes up by 0 standard deviations. This is in addition to any indirect (mediated) effect that AIBSD may have on AIBSD (Table 9). 
Table 9. Standardized indirect effects.

\begin{tabular}{|c|c|c|c|c|}
\hline & $\mathrm{HCD}$ & SCD & AERD & AIBSD \\
\hline Social capital dimension (SCD) & 0.000 & 0.000 & 0.000 & 0.000 \\
\hline Access to external resource dimension (AERD) & 0.005 & 0.000 & 0.000 & 0.000 \\
\hline Internal capabilities and business structure dimension (IBSD) & 0.007 & 0.002 & 0.000 & 0.000 \\
\hline Sales growth & -0.517 & 0.164 & -0.083 & 0.000 \\
\hline Number of new product introduced & 0.063 & -0.018 & 0.009 & 0.000 \\
\hline Introduction of new machines & 0.371 & -0.106 & 0.054 & 0.000 \\
\hline Innovation and imitation & 0.741 & -0.211 & 0.108 & 0.000 \\
\hline Access to markets & 0.680 & 0.011 & 0.000 & 0.000 \\
\hline Supportive network with financial institutions & 0.001 & 0.000 & 0.000 & 0.000 \\
\hline Market related innovations with employ benefits & 0.276 & -0.079 & 0.040 & 0.000 \\
\hline Ownership structure with stock related innovations & 0.267 & -0.076 & 0.039 & 0.000 \\
\hline Sharing consultancy with social network & 0.010 & 0.000 & 0.000 & 0.000 \\
\hline Government supportive activities & 0.017 & 0.000 & 0.000 & 0.000 \\
\hline Resource sharing with SMEs & 0.352 & 0.000 & 0.000 & 0.000 \\
\hline Organizational network and network maintenance & 0.362 & 0.000 & 0.000 & 0.000 \\
\hline Technical and professional education & 0.000 & 0.000 & 0.000 & 0.000 \\
\hline Ownership experience in same field & 0.000 & 0.000 & 0.000 & 0.000 \\
\hline Family tradition & 0.000 & 0.000 & 0.000 & 0.000 \\
\hline Self-learning with ownership experience in different field & 0.000 & 0.000 & 0.000 & 0.000 \\
\hline Self-learning with work experience in different field & 0.000 & 0.000 & 0.000 & 0.000 \\
\hline Competition from large and medium enterprises & 0.445 & 0.007 & 0.000 & 0.000 \\
\hline Suppliers availability & 0.687 & 0.011 & 0.000 & 0.000 \\
\hline Capital Sources with credit from finance companies & 0.670 & 0.011 & 0.000 & 0.000 \\
\hline Access to inputs & 0.300 & 0.005 & 0.000 & 0.000 \\
\hline Access to credit and credit information & 0.467 & 0.007 & 0.000 & 0.000 \\
\hline Education with experience in government sector & 0.000 & 0.000 & 0.000 & 0.000 \\
\hline Training with work experience in same field & 0.000 & 0.000 & 0.000 & 0.000 \\
\hline
\end{tabular}

Source: Survey data (2016).

As presented in Table 9, the standardized indirect (mediated) effect of HCD on sales growth is -0.517 . That is, due to the indirect (mediated) effect of HCD on sales growth, when HCD goes up by 1 standard deviation, sales growth goes down by 0.517 standard deviations. This is in addition to any direct (unmediated) effect that HCD may have on sales growth. The standardized indirect (mediated) effect of SCD on sales growth is 0.164 . That is, due to the indirect (mediated) effect of SCD on sales growth, when SCD goes up by 1 standard deviation, sales growth goes up by 0.164 standard deviations. This is in addition to any direct (unmediated) effect that SCD may have on sales growth. The standardized indirect (mediated) effect of AERD on sales growth is -0.083 . That is, due 
to the indirect (mediated) effect of AERD on sales growth, when AERD goes up by 1 standard deviation, sales growth goes down by 0.083 standard deviations. This is in addition to any direct (unmediated) effect that AERD may have on sales growth. The standardized indirect (mediated) effect of AIBSD on sales growth is 0.000 . That is, due to the indirect (mediated) effect of AIBSD on sales growth, when AIBSD goes up by 1 standard deviation, sales growth goes up by 0 standard deviations. This is in addition to any direct (unmediated) effect that AIBSD may have on sales growth.

The data in the tables pointed out in particular, training with work experience in same field has substantial positive effect on employee growth. In addition to the direct effect, it has indirect positive effect on employee growth via variables in social capital (i.e. organizational network with network maintenance and resources sharing with SEs) and internal capabilities \& business structure (i.e. number of products with employee incentives). This finding contributes to the human capital literature. According to Rauch et al. (2005), empirical studies on human capital unfortunately, have seldom analyzed the mechanisms through which human capital leads to business success. Firms with more experienced, educated and trained entrepreneurs grow more rapidly than those with entrepreneurs possessing smaller stocks of human capital. These findings suggest some supportive measures aimed at promoting human capital formation. Government can launch policies aimed at influencing the knowledge and skills of individuals. Policy measures to develop human capital might include training and technical assistance programs. The study highlighted the importance of social capital for employee growth. Organizational networks with network maintenance and resources sharing with SEs have greater positive influence on employee growth. Resources sharing with SEs imply the sharing resources among SEs for mutual benefits.

No doubt, resources are very important for any kinds of enterprises. Some small enterprises have limited availability of some kind of resources while they may have excess in other kind of resources. The development and maintenances of organizational networks pave the ways to sharing resources and information among network member. The results with respect to access to external resources reveal both direct and indirect effects on employee growth. Especially, access to inputs has substantial significant positive effect on employee growth. Access to inputs comprised with labor, raw material and finance. In the case of internal capabilities and business structure, the data suggest that it has direct positive effect on employee growth. Two variables namely innovations and imitations and number of products with employee incentives have significant positive effect on employee growth. This finding suggests that the owner-managers of small enterprises in Gurage Zone can achieve higher growth through following different form of innovations and imitations such as product, process, work practice, marketing and supply relations. This can be realized by intensifying the existing contacts with organizational networks and enhancing the human capital through 
training and experience. Collaboration with business support institutions and other organizations can serve to acquire the expertise and services that currently are lacking in the industry. One of most important finding of this study is that human capital, social capital, access to external resources, internal capabilities \& business structure predict small enterprise growth better when the web of complex indirect relationships should be included than only multiple simultaneous direct effects are studied. Furthermore, it shows that all research dimensions in the prediction of small enterprise growth and total effects should be considered, and that small enterprise growth cannot be adequately explained from a single perspective. In sum, the study has shown that employee growth is to a certain extent externally determined, but entrepreneur related human and social capital and firm-related internal capabilities \& business structure also have effects on employee growth. From the point of view of entrepreneurs, this research suggests that they should recognize that multiple dimensions affect success. According to the suggestions provided by (Nishantha, 2011) future researches of employee growth in SEs are encouraged to investigate SEs in a specific industry, for example, service sectors, to compare the differences in different industries. In line with their suggestions this research tries to fit the model for each sector in particular and for the general SME's operators.

\subsection{Discussion Result of Focus Group}

Related to Human capital dimension, the FGD participants revealed that enterprises that join in the business with experience and education (formal or informal) are more successful compared to its counter parts. MSE's which involve in the business with knowledge gap in all dimension of the business is more unlikely to be successful. Most of these operators are running their business by their own practice, they do not get training from the government (there is gap). But recently there is some improvement regarding this. Especially, technical and TVET education has great impact on the success of MSE's. Related to Social Capital Dimension, almost in all FGD areas it is founded that social capital is the most important determinant that affect MSE's growth. And what the researcher founded is that there is gap (lack of social capital) among MSE's operators. Even FGD participant recommend that if these enterprises have social capital they will be grow more and they will become more successful. Especially resource sharing with MSE's, finance access from finance companies and government supportive activities have great impact on the success of MSE's. Accesses to External Resources Dimension, accesses from external sources like financial institution (bank, MFI and input suppliers) are chronic problem for MSE's in this zone. Bank cannot lend without adequate collateral for MSE's operators, but if MSE's owners want to borrow from private bank and MFI they are charge high interest rate. Even there is religion-interest dilemma. There is also acute shortage of input for production (the supplier may be government or private sector). But only few NGO give finance access to women owner MSE's owner without interest 
charge. Internal Capabilities and Business Structure Dimension, most of MSE's are imitators rather than innovating new products, product distribution, marketing and production process. The form of business MSE's operating is partnership (associations). There is no employee benefit other than salary like bonus and fringe benefit. But what they conclude is these all things have impact on MSE's growth.

\subsection{Model Fit}

The initial Four-Dimension employee and sales growth determinants CFA model did not fit well, with $\chi^{2}=1442.705, \mathrm{DF}=539$, and $P$ less than 0.0005 . In addition to the fit indices recommended by Brown (2006), Amos provides a number of additional fit indices; although not all fit indices are recommended. Using Brown's (2006) recommendations of RMSEA close to 0.06 or less; CFI close to 0.95 or greater; and TLI close to 0.95 or greater, we see that this model does not fit well, with RMSEA $=0.119, \mathrm{CFI}=0.728$, and TLI $=0.7$. These fit indices suggest that the model needs to be modified. According to (Donna, 2009) an additional benefit of having a data set without missing data in Amos 7.0 is that you can obtain normality checks, including skewness and kurtosis indexes. In this study Mardia's coefficient is 137.226 and critical ratio is 14.769 . So according to the criteria provided in the methodology part of this study kurtosis and skewness do not appear problematic for this study.

\section{Conclusion and Recommendations}

The objective of this study is to determine the relative contribution of different dimensions and identify the important factors effect growth of micro and small enterprises in Gurage zone. Based on the literature developed in the field of small enterprises, a contingent model has been adapted in which human capital, social capital, access to external resources and internal capabilities and business structure affect sales and growth. The model has been estimated by using standardized multiple regression coefficients as coefficients, on a sample of 320 MSE. According to the path analysis results, internal capabilities and business structure is the key dimension that directly affects sales growth through variables namely innovation and imitations and number of products with employee incentives. It followed by human capital, social capital and access to external resources. A number of variables influence employee growth. These may affect the growth directly, indirectly, or both. As expected, human capital of owner-managers of MSE's had direct and indirect on growth. In particular, training with work experience in same field has substantial positive effect on growth. In addition to the direct effect, it has indirect positive effect on growth via variables in social capital (i.e. organizational network with network maintenance and resources sharing with MSE's) and internal capabilities and business structure (i.e. number of products with employee incentives). This finding contributes to the human capital literature. According to Rauch et al. (2005), empirical studies on human 
capital unfortunately, have seldom analyzed the mechanisms through which human capital leads to business success. Firms with more experienced, educated and trained entrepreneurs grow more rapidly than those with entrepreneurs possessing smaller stocks of human capital. The results with respect to access to external resources reveal both direct and indirect effects on employee growth. Especially, access to inputs has substantial significant positive effect on employee growth. Access to inputs is comprised with labor, raw material and finance. In the case of internal capabilities and business structure, the data suggest that it has direct positive effect on growth. Two variables namely innovations and imitations and number of products with employee incentives have significant positive effect on growth. This finding suggests that the owner-managers of small enterprises in Gurage Zone can achieve higher growth through following different form of innovations and imitations such as product, process, work practice, marketing and supply relations. This can be realized by intensifying existing contacts with organizational networks and enhancing the human capital through training and experience. Collaboration with business support institutions and other organizations can serve to acquire the expertise and services that currently are lacking in the industry.

These findings suggest some supportive measures aimed at promoting human capital formation. Government can launch policies aimed at influencing the knowledge and skills of individuals. Policy measures to develop human capital might include training and technical assistance programs. The study highlighted the importance of social capital for MSE's growth. Organizational networks with network maintenance and resources sharing with MSE's have greater positive influence on growth. Resources sharing with MSE's imply the sharing resources among them for mutual benefits. No doubt, resources are very important for any kinds of enterprises. Some small enterprises have limited availability of some kind of resources while they may have excess in other kind of resources. The development and maintenances of organizational networks pave the ways to sharing resources and information among network members. In sum, the study has shown that growth is to a certain extent externally determined, but entrepreneur related human and social capital and firm-related internal capabilities and business structure also have effects on MSE's growth. From the point of view of entrepreneurs, this research suggests that they should recognize that multiple dimensions affect success. Future researches on the determinants of growth in MSE's are encouraged to investigate the sectors in a broader area. The nature of the influence of human capital, social capital, access to external resources and internal capabilities and business structure remains an interesting issue for future research.

\section{Conflicts of Interest}

The authors declare no conflicts of interest regarding the publication of this paper. 


\section{References}

Abeka, O. E. (2011). Networks, Micro Small Enterprises (MSE'S) and Performance: The Case of Kenya. African Research Review, 5, 172-187. https://doi.org/10.4314/afrrev.v5i6.15

Arbuckle, J. L. (2012). IBM SPSS Amos 21 Users Guide. Chicago, IL: IBM Software Group.

Brown, T. A. (2006). Confirmatory Factor Analysis for Applied Research. New York: The Guilford Press.

Chin, W. W. (1998). The Partial Least Squares Approach for Structural Equation Modeling. In G. A. Marcoulides (Ed.), Methodology for Business and Management. Modern Methods for Business Research (pp. 295-336). USA: Lawrence Erlbaum Associates Publishers.

Darnay, A. J., \& Magee, M. D. (2007). Encyclopedia of Small Business (3rd ed., Vol. 1 \& 2). Farmington Hills, MI: Thomson Gale.

Davidsson, P. (1989). Entrepreneurship-and After? A Study of Growth Willingness in Small Firms. Journal of Business Venturing, 4, 211-226. https://doi.org/10.1016/0883-9026(89)90022-0

Degenhardt, S. S., Stamm, A., \& Zehdnicker, M. (2002). The Growth Gap: A Small Enterprise Phenomenon, Synthesis Document (pp. 1-17). El Salvador, Germany, Spain: The Donor Committee for Enterprise Development German.

Donna, H. (2009). Confirmatory Factor Analysis: Pocket Guides to Social Work Research Methods (T. Tony, Ed.). New York: Oxford University Press, Inc.

Hair, J. F., Hult, G. M., Ringle, C. M., \& Sarstedt, M. (2014). A Premier on Partial Least Squares Structural Equation Modeling (PLS-SEM). California: SAGE Publications, Inc.

Hair, J., Anderson, R., Tatham, R., \& Black, W. (1995). Multivariate Data Analysis (5th ed.). Upper Saddle River, NJ: Prentice-Hall.

Hair, J., Black, W., Babin, B., Anderson, R., \& Tatham, R. (2006). Multivariate Data Analysis (6th ed.). Upper Saddle River, NJ: Prentice-Hall.

Kline, R. B. (1998). Methodology in Social Sciences.Principles and Practice of Structural Equation Modeling (4th ed.), Washington, USA: Guilford Press.

Liedholm, C., McPherson, M. A., \& Chuta, F. (1994). Small Enterprise Employment Growth in Rural Africa. American Journal of Agricultural Economics, 76, 1177-1182. https://doi.org/10.2307/1243413

Nishantha, B. (2011). The Role of Social Capital on Firm Growth: The Case of Small Enterprises in Sri Lanka. Asia Pacific World, 2, 54-71. https://doi.org/10.3167/apw.2011020104

Nishantha, B. (2013). Factors Contributing to the Growth of Small Enterprises (SEs) in SriLanka: A Comparison of Sales and Employee Growth Models. Sri Lanka Journal of Management, 52, 259-277.

Nunnally, J. C. (1978). Psychometric Theory (2nd ed.). New York: McGraw-Hill.

Pallant, J. (2005). SPSS Survival Guide to Data Analysis Using SPSS for Windows (3rd ed.). New York: Open University Press.

Rami, A., \& Ahmed, A. (2007). Critical Analysis And Modelling Of Small Business Performance (Case Study: Syria). Journal of Asia Entrepreneurship and Sustainability, 3(2). Retrieved from Editors@asiaentrepreneurshipjournal.com

Rauch, A., Frese, M., \& Utsch, A. (2005). Effects of Human Capital and Long-Term Hu- 
man Resource Development and Utilization on Employment Growth of Small Scale Businesses. Entrepreneurship Theory \& Practices, 29, 681-689.

Robert, B. (2007). Multilevel Analysis for Applied Research It's Just Regression! (K. A. David, Ed.). New York: Guilford Press.

Tabachnick, B. G. (2007). Using Multivariate Statistics (5th ed.). Boston, MA: Allyn \& Bacon/Pearson Education.

Wiklund, J. (2009). Building an Integrative Model of Small Business Growth. Journal of Small Business Economics, 39, 351-374. https://doi.org/10.1007/s11187-007-9084-8

World Bank, The Japan International Cooperation Agency, The Foundation for Advanced Studies on International Development, and Economists Affiliated with the African Economic Research Consortium (2011). Industrial Clusters and Micro and Small Enterprises in Africa: From Survival to Growth. Washington, DC: The World Bank.

Yamane, T. (1967). Statistics: An Introductory Analysis (2nd ed.). New York: Harper and Row. 